\title{
Diagnóstico ambiental do trecho urbano do ribeirão Tangará em Cornélio Procópio (PR): uma proposta didática para educação ambiental
}

\author{
Environmental diagnosis of the urban section of Tangará stream in \\ Cornélio Procópio (PR): a teaching proposal for environmental education
}

\author{
Francyne Willy da Silva \\ Paulo Henrique Marques de Castro $^{B}$ \\ a Acadêmica do curso de licenciatura em Geografia da \\ Universidade Estadual do Norte do Paraná (Uenp). \\ E-mail: cynesilva@hotmail.com

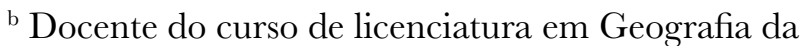 \\ Universidade Estadual do Norte do Paraná (Uenp). \\ E-mail: paulocastro@uenp.edu.br
}

\begin{abstract}
O ribeirão Tangará tem a sua área de nascente localizada no município de Cornélio Procópio, Paraná (PR) e percorre aproximadamente $30 \mathrm{~km}$ até sua foz, no rio Congonhas, entre os municípios de Leópolis $(\mathrm{PR})$ e Sertaneja (PR). O recorte espacial de análise compreende o trecho urbano do ribeirão Tangará, que corresponde à região da nascente e a parte do alto curso do ribeirão. O objetivo principal desta pesquisa é realização de um diagnóstico ambiental da área, principalmente em relação à avaliação das Áreas de Preservação Permanente (APP), com base na Lei n ${ }^{\circ}$ 12.651, de 2012. Metodologicamente, a pesquisa esteve orientada em duas frentes: a realização do diagnóstico ambiental no trecho urbano do ribeirão Tangará e a elaboração de uma proposta didática voltada à Educação Ambiental pautada no uso de geotecnologias a partir de ferramentas do Google: Google Earth Pro, Google My Maps e Google Sites. A partir dos resultados, constatou-se que o ribeirão vem sofrendo impactos negativos, provenientes da urbanização. Quanto à proposta de Educação Ambiental, houve a elaboração e compartilhamento do mapeamento virtual do ribeirão Tangará na plataforma Google My Maps com características atuais do ribeirão. Além disso, construiu-se uma cartilha virtual no formato de site para divulgar informações sobre o ribeirão Tangará.
\end{abstract}

Palavras-chave: ribeirão Tangará, Cornélio Procópio (PR), Educação Ambiental.

\begin{abstract}
The source of the Tangará stream is located at the municipality of Cornélio Procópio (PR), covering approximately $30 \mathrm{~km}$ until its mouth, on the Congonhas River, between the municipalities of Leópolis (PR) and Sertaneja (PR). The spatial analysis comprises the urban stretch of the Tangara stream, including the source region and part of its upstream. This study sought to perform an environmental diagnosis of the area, especially regarding Permanent Preservation Areas (PPA), based on Law No. 12,651/12. Two fronts comprised the methodology of this research: the environmental diagnosis in the urban stretch of the Tangará stream; and the elaboration of a teaching proposal for Environmental Education based on geotechnological tools from Google, namely the Google Earth Pro, Google My Maps, and Google Sites. The results indicate that urbanization has had a negative impact on the stream. Regarding the teaching proposal, a virtual mapping of the Tangará stream was developed and made available on the Google My Maps platform, including all current features of the stream. The proposal also comprised the production of a Virtual Booklet in the format of a website, disseminating information about the Tangará stream.
\end{abstract}

Keywords: Tangará stream, Cornélio Procópio (PR), Environmental Education. 


\section{INTRODUÇÃO}

O município de Cornélio Procópio, localizado no norte do estado do Paraná, região Sul do Brasil, abriga o alto curso do ribeirão Tangará, inclusive a região da nascente. $\mathrm{O}$ recorte espacial desta pesquisa compreende o trecho urbano do ribeirão Tangará, para a realização de um diagnóstico ambiental.

A ciência geográfica busca estudar o espaço geográfico, ou seja, o espaço apropriado e produzido pelo homem. Dessa forma, passamos a analisar as ações do homem no espaço, visto que nos últimos anos a ação humana na natureza tem gerado sérios problemas socioambientais. No trecho do ribeirão Tangará estudado, observa-se a poluição ambiental gerada pela população, como o descarte inadequado de lixo de diferentes origens - industrial, doméstico, entre outros. Diferentemente do centro da cidade, que recebe atenção relativamente maior do poder público e da população de modo geral, na área estudada, por ser um local afastado, os impactos ambientais acontecem com maior frequência.

O presente trabalho visa à realização de um diagnóstico ambiental, pautado sobretudo na avaliação das áreas de mata ciliar do rio. A Lei n ${ }^{\circ}$ 12.651/2012 dispõe sobre áreas de preservação permanente (APP) que inserem alguns espaços como morros, montanhas, nascentes ou olho d'água, assim como a mata ciliar presente nas margens dos rios (BRASIL, 2012). Além disso, a partir do estudo foi elaborada uma proposta didática voltada à Educação Ambiental que consistiu na realização do mapeamento virtual do ribeirão Tangará, assim como na elaboração de uma cartilha virtual no formato de site, para divulgar informações e conteúdos relacionados à temática do estudo, difundindo, dessa forma, o uso de ferramentas relacionadas às geotecnologias.

Para realização do trabalho, fizeram-se levantamentos bibliográficos sobre a temática da pesquisa, assim como trabalhos de campo. Em relação à proposta didática voltada à Educação Ambiental foram empregadas ferramentas do Google, como: Google Earth Pro, Google My Maps e Google Sites, por serem gratuitas, amplamente utilizadas e de fácil divulgação, acesso e manuseio.

Este trabalho justifica-se pela ausência de pesquisas relacionadas ao ribeirão Tangará. Nesse contexto ainda há de se destacar que na região do ribeirão se localiza uma área de expansão urbana de Cornélio Procópio, onde recentemente foram construídos novos bairros. Além disso, a pesquisa dispõe de material didático que pode ser aplicado nas aulas de Geografia, nos temas que abordam a questão ambiental. Dessa forma, é pretensão desta pesquisa a sua utilização para a difusão de conhecimento relacionado ao ribeirão Tangará e da proposta didática como complemento de conteúdos de Educação Ambiental, a partir de uma linguagem inovadora, que agrega a utilização de ferramentas geotecnológicas.

\section{Pressupostos teóRICos}

Há muito tempo, a natureza sofre impactos por parte da sociedade, em diferentes magnitudes. Esses impactos ocasionam problemas ambientais como deslizamentos, erosão do solo, degradação da fauna e flora, assoreamento dos rios etc. Analisando a perspectiva da relação entre sociedade e natureza na Geografia sob a óptica de um geógrafo, Veyret (1999, p. 6, tradução nossa) afirma sobre a abordagem ambiental que:

De fato, para um geógrafo, a noção de meio ambiente não recobre somente a natureza, ainda menos a fauna e a flora somente. Este termo designa as relações de interdependência que existem entre o homem, as sociedades e os componentes físicos, químicos, bióticos do meio e integra também seus aspectos econômicos, sociais e culturais.

Sendo assim, estudar o meio ambiente requer também entender todos os objetos que estão relacionados a ele. Francisco Mendonça (2001, p. 117) comenta da seguinte forma:

[...] o que leva a crer que tenha sido gerada uma concepção cultural do meio ambiente que exclui a sociedade da condição de componente/sujeito, mas a inclui como agente/ fator. Inserir na abordagem ambiental a perspectiva humana portanto social, econômica, política e cultural.

Portanto, a sociedade é entendida como um agente no ambiente, exercendo um papel sobre ele, que deve ser estudado. A partir desse pensamento, surge o termo "socioambiental", que entrelaça "sócio" e "ambiente" para enfatizar a relação da sociedade enquanto sujeito dos problemas ambientais contemporâneos (MENDONÇA, F., 1993; 2001). 


\section{IMPACTOS AMBIENTAIS, EDUCAÇÃO AMBI- ENTAL E PRESERVAÇÃO}

Os impactos ambientais sempre estiveram presentes na sociedade e atualmente não é diferente, o que é extremamente preocupante, uma vez que podem ser irreversíveis ou de longa duração, causando sérios danos. Encontramos facilmente resquícios de impactos ambientais em pontos periféricos de algumas cidades, e em pontos mais afastados como nas áreas rurais. Um dos impactos mais comuns encontrados nessas áreas é a poluição, que pode ser "[...] hídrica, do solo, e da atmosfera. Quanto à natureza dos agentes poluidores, esses ambientes podem ser contaminados por compostos químicos, esgotos, resíduos eletrônicos e orgânicos" (VIANNA, 2015, p. 25). Segundo a Lei n ${ }^{\circ}$ 6. 938, de 31 de agosto de 1981, Art. $3^{\circ}$, III, entende-se por:

III- poluição, a degradação da qualidade ambiental resultante de atividade que direta ou indiretamente;

a. prejudiquem a saúde, a segurança e o bem-estar da população;

b. criem condições adversas às atividades sociais e econômicas;

c. afetem desfavoravelmente a biota;

d. afetam as condições estéticas ou sanitárias do meio ambiente;

e. lancem matérias ou energia em desacordo com os padrões ambientais estabelecidos. (BRASIL, 1981)

O crescimento urbano e o setor industrial, assim como o setor agropecuário, cuja demanda por terras cresce cada vez mais para produzir grãos ou criar gado, vêm causando o desmatamento e a degradação das terras, o que eleva ainda mais a procura por recursos naturais. Segundo Santos e Faria (2004), há séculos a humanidade conheceu a natureza e logo a modificou, de acordo com suas necessidades, de forma que novas técnicas e ferramentas foram surgindo para sua modificação, decorrentes da demanda do consumo e da produção.

O uso dos recursos naturais nas últimas décadas vem sendo uma das preocupações e questionamento por parte dos profissionais e da própria população, a grande discussão é sobre a preservação ambiental e a recuperação das áreas que sofrem processos de degradação. $\mathrm{O}$ desenvolvimento socioeconômico decorrente do crescimento industrial e agrícola juntamente com o crescimento populacional do mundo, tem aumentado significativamente a demanda sobre os recursos naturais, sendo que esta demanda é considerada bem maior que a capacidade de reposição dos recursos. (FERREIRA, 2015 apud SILVA et al., 2018, p. 2)

Justamente por essa procura por recursos naturais e a degradação acelerada do meio, nos questionamos quais tipos de problemas podem surgir. Um deles é a degradação de APP, como as matas ciliares, conforme Fernandes et al. (2015) destacam "[...] a degradação do meio ambiente vem contribuindo para a poluição das águas, pois as matas ciliares são fundamentais para a proteção dos recursos hídricos. Podendo comprometer a quantidade de água disponível e a qualidade de água potável".

O crescimento acelerado das cidades é outro fator que, direta ou indiretamente, por vezes causa sérios danos ambientais, uma vez que favorece a construção de domicílios urbanos de forma desordenada em áreas que deveriam ser preservadas para manter o equilíbrio ecológico e hidrológico de uma microbacia (SANTANA, 2011). Além disso, há de se destacar consequências como: moradias em áreas inadequadas que resultam em deslizamentos em épocas de chuvas; a falta de saneamento básico; poluição do meio ambiente; falta de coleto de lixo adequada e moradias precárias (MOTA, 2003).

Portanto, entender os impactos ambientais é fundamental para manter o equilíbrio entre a sociedade e meio ambiente, para que os recursos sejam utilizados de maneira apropriada e novas políticas e formas de combater os impactos ambientais sejam criadas. Como podemos definir então o impacto ambiental? Moreira (1992) o define como qualquer alteração no meio ambiente em um ou mais de seus componentes provocado por ação humana. De acordo com a Norma Brasileira de Regulamentação ISO 14001/2015, impacto ambiental é "modificação no meio ambiente, tanto adversa como benéfica, total ou parcialmente resultante dos aspectos ambientais de uma organização" (ABNT, 2015, p. 3).

Sendo assim, a Educação Ambiental está destinada a sensibilizar a sociedade sobre os caminhos a serem seguidos, pautados na conservação do meio ambiente, conforme a Lei $\mathrm{n}^{\circ}$ 9.795, de 27 de abril de 1999, Capítulo I, Art. $1^{\circ}$ coloca:

Entende-se por educação ambiental os processos por meio dos quais o indivíduo e a coletividade constroem valores sociais, conhecimentos, habilidades, atitudes e competências 
voltadas a conservação do meio ambiente, bem de uso comum do povo, essencial á sadia qualidade de vida e sua sustentabilidade. (BRASIL, 1999)

Inserida nas escolas, ela ensina aos alunos a importância do meio ambiente e de sua preservação. Segundo o Art. $2^{\circ}$ da Lei no 9.795/99 "a educação ambiental é um componente essencial e permanente da educação nacional, devendo estar presente, de forma articulada, em todos os níveis e modalidades do processo educativo, em caráter formal e não formal” (BRASIL, 1999).

Conforme a lei, a Educação Ambiental está inserida na educação não formal e, de acordo com a Seção III, Art. 13, deve-se possibilitar "ações e práticas educativas voltadas à sensibilização da coletividade sobre as questões ambientais e à sua organização e participação na defesa da qualidade do meio ambiente" (BRASIL, 1999). A Educação Ambiental fora das escolas procura orientar as pessoas sobre ações que devem ser seguidas e, se a população aderisse a elas, resultaria em uma melhor interação com o meio ambiente, possibilitando um futuro melhor para as próximas gerações.

Os Parâmetros Curriculares Nacionais (PGN) (BRASIL, 1997, p. 17) apontam que "a educação para a cidadania perpassa pelas questões sociais que requer que sejam apresentados para a aprendizagem e reflexão dos alunos, buscando um tratamento didático mais flexível e dinâmico".

Com base nessa ideia, os PCN destacam:

Perspectiva ambiental oferece instrumentos para que o aluno possa compreender problemas que afetam a sua vida, a de sua comunidade, a de seu país e a do planeta. Para que essas informações os sensibilizem e provoquem o início de um processo de mudança de comportamento, é preciso que o aprendizado seja significativo, isto é, os alunos possam estabelecer ligações entre o que aprendem e a sua realidade cotidiana, e o que já conhecem. [...] nesse sentido, o ensino deve ser organizado de forma a proporcionar oportunidades para que os alunos possam utilizar o conhecimento sobre meio ambiente, para compreender a sua realidade e atuar sobre ela, por meio do exercício da participação em diferentes instâncias. (BRASIL, 1997, p. 48)

Compreende-se que a Educação Ambiental deve ser planejada na escola em conciliação com a realidade do país, do estado ou, principalmente, do local onde o aluno se encontra. Dessa forma, é possível o professor mediar e transferir conhecimentos significativos. Guimarães (1995, p. 14) afirma que [a] Educação Ambiental se trata de uma dimensão do processo educativo, voltada para a participação de seus atores, educandos e educadores, para a construção de um novo paradigma que comtemple os anseios populares para uma melhor qualidade de vida socioeconômica, e um mundo ambientalmente sadio.

Segundo Campiani (2001), os professores devem aprender novos conceitos e metodologias com base na realidade, a fim de se tornarem atuantes e críticos ante as situações socioambientais, podendo atuar e influenciar nas mudanças de atitude. $\mathrm{O}$ autor destaca a importância da atuação do poder público, através do Ministério da Educação (MEC), para estimular a capacitação maciça, no caso da educação formal, e do cidadão por meio do exercício da cidadania.

A Educação Ambiental é tratada nas escolas de maneira interdisciplinar, incluída de forma transversal, conforme os PCN (BRASIL, 2001). Os professores devem ser capacitados mediante formações continuadas, para transmitiram aos alunos os saberes e condutas relacionadas à Educação Ambiental, de forma que contemplem a realidade dos estudantes. Assim, é necessário dar atenção às questões ambientais do país, do estado e das cidades em que atuam, para que a Educação Ambiental adquira caráter significativo na formação do aluno.

\section{ÁREAS DE PRESERVAÇÃO PERMANENTE $(\mathrm{APP})$}

A Constituição Federal (CF), art. 225, § $1^{\circ}$, III, afirma que todos têm direito a um meio ambiente ecologicamente equilibrado, condição essencial para a qualidade de vida, e impõe ao poder público e à coletividade o dever de defendê-lo e preservá-lo para as presentes e futuras gerações, assim como determina que o poder público tem obrigação de criar espaços protegidos por lei em todas as unidades da federação (SCHÄFFER et al., 2011).

De acordo com o artigo $3^{\circ} /$ II da Lei n ${ }^{\circ}$ 12.651/2012, entende-se por APP, “área protegida, coberta ou não por vegetação nativa, com a função ambiental de preservar os recursos hídricos, a paisagem, a estabilidade geológica e a biodiversidade, facilitar o fluxo gênico de fauna e flora, proteger o solo e assegurar o bem-estar das populações humanas" (BRASIL, 2012).

As APP desenvolvem um papel essencial para proteger o meio ambiente em si e a qualidade de vida da população. Isso é notório quando pensamos em alguns acontecimentos 
recentes do Brasil, como no caso da notícia "Na tragédia de Minas, o descaso da administração encontra os efeitos da mudança climática", que trata da forte chuva que atingiu Belo Horizonte, causando estragos severos e várias mortes. Esses danos foram ocasionados por uma má urbanização da cidade, que ignorou o curso dos rios, dificultando seu escoamento e causando alagamentos (MENDONÇA, 2020).

De acordo com o Capítulo II, Seção 1, art. 4 " "considera-se APP, em zonas rurais ou urbanas, para os efeitos desta Lei” (BRASIL, 2012). É considerada uma APP qualquer faixa de cursos d'água perene ou intermitente, excluídos os efêmeros, conforme a Lei no 12.651/2012. Dessa forma, entende-se por APP:

I - As faixas marginais de qualquer curso d'água natural, perene e intermitente, excluídos os efêmeros, desde a borda da calha do leito regular, em largura mínima de: (Incluído pela Lei $\mathrm{n}^{\circ} 12.727$, de 2012).

a. 30 (trinta) metros para os cursos d'água de menos de 10 (dez) metros de largura;

b. 50 (cinquenta) metros para os cursos d'água que tenham de 10 (dez) a 50 (cinquenta) metros de largura;

c. 100 (cem) metros para os cursos d'água que tenham de 50 (cinquenta) a 200 (duzentos) metros de largura;

d. 200 (duzentos) metros para os cursos d'água que tenham de 200 (duzentos) a 600 (seiscentos) metros de largura;

e. 500 (quinhentos) metros para os cursos d'água que tenham largura superior a 600 (seiscentos) metros;

\section{$[\ldots]$}

IV - As áreas no entorno das nascentes e dos olhos d'água perenes, qualquer que seja sua situação topográfica, no raio mínimo de 50 (cinquenta) metros. (BRASIL, 2012)

Conforme o Art. 6º da Lei n ${ }^{\circ}$ 12.651/2012, consideram-se áreas de APP aquelas de interesse social do chefe do Poder Executivo, cobertas por florestas ou outras formas de vegetação, para os devidos fins, como: conter a erosão, diminuindo riscos de deslizamentos e enchentes; proteger restingas e veredas; abrigar a fauna e a flora, principalmente espécies ameaçadas de extinção; proteger sítios de excepcional beleza, de valor científico, cultural ou histórico; proteger faixas de proteção ao longo de rodovias e ferrovias; promover boas condições de bem-estar público; promover auxílio de defesa do território nacional, a critério das autoridades militares e proteção de áreas úmidas, principalmente as de importância internacional.

\section{Ribeirão TANGARÁ}

O ribeirão Tangará se localiza na região do Norte Pioneiro do estado do Paraná, entre os municípios de Cornélio Procópio, Leópolis e Sertaneja. Segundo o Plano Diretor Municipal de Cornélio Procópio (2007, p. 19) “[ [... nas proximidades da cidade localizam-se as nascentes dos principais cursos de água do município, que são: os ribeirões Tangará, São Luiz e Macuco, e o rio Água do Veado". O ribeirão Tangará percorre uma extensão de cerca de $30 \mathrm{~km}$ em direção oeste, até a sua foz, no rio Congonhas (figura 1). Este último, por sua vez, tem sua foz no rio Tibagi, um dos mais expressivos rios do estado do Paraná.

Figura 1. Localização do ribeirão Tangará.

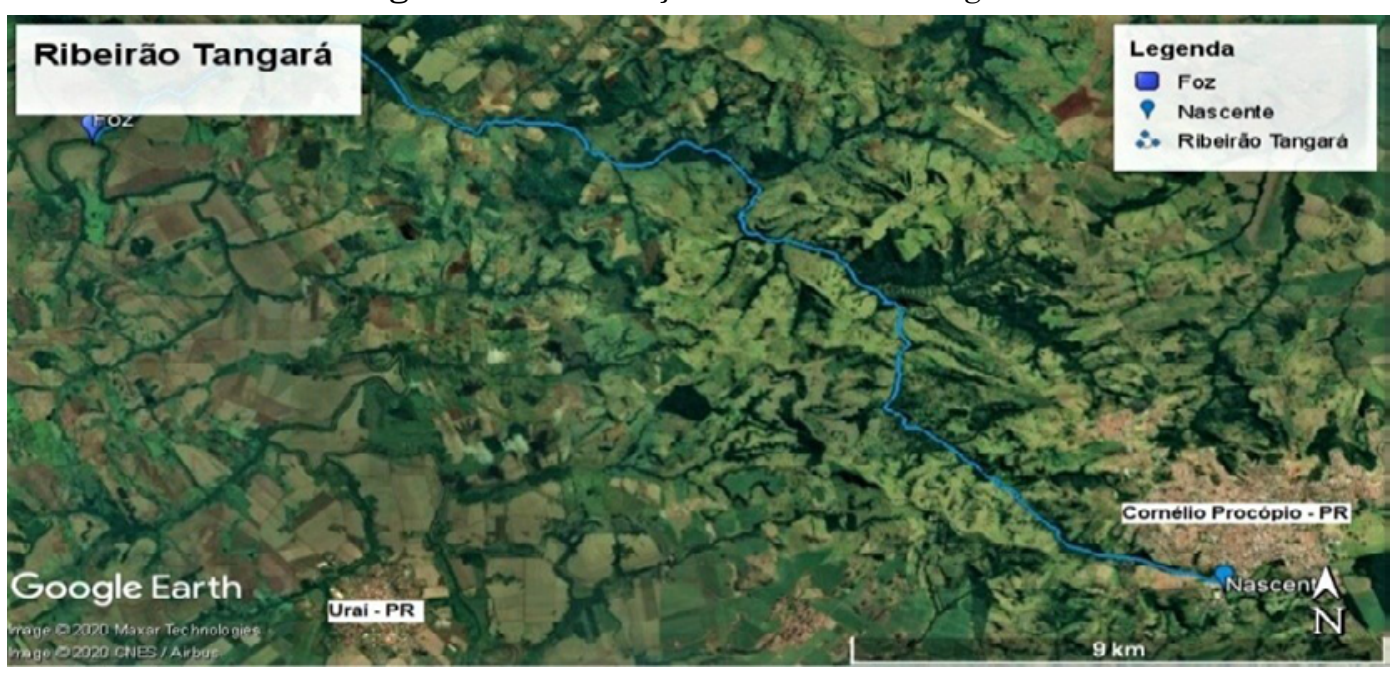

Fonte: Google Earth (2020). 
De acordo com o Plano Diretor Municipal de Cornélio Procópio (2007, p. 19), o ribeirão Tangará, com sua rede de drenagem, compõe uma sub-bacia hidrográfica, a qual está integrada à bacia hidrográfica do rio Tibagi (macrobacia), e [...] "as demais sub-bacias, principalmente a do ribeirão Tangará possui uma topografia irregular e uma drenagem mais densa". O documento ainda afirma:

\begin{abstract}
A região de Cornélio Procópio integra a unidade geomorfologica regionalmente denominada Terceiro Planalto, que, em conjunto com o Segundo Planalto, ocupa 2/3 da área do estado do Paraná, dentro da unidade morfoestrutural da bacia sedimentar do Paraná. O Terceiro Planalto ou Planalto de Trapp é o resultado dos derrames de rochas eruptivas, como basalto, diabasico, melafinos da formação Serra Geral e em menores proporções encontram-se os depósitos de arenitos da formação Botucatu da era Mesozóica. (CORNÉLIO PROCÓPIO, 2007, p. 23)
\end{abstract}

Segundo Pereira e Scroccaro (2010), a região em que se encontra o ribeirão Tangará pertence à unidade aquífera Serra Geral Norte. Tal afirmação é corroborada por Medri et al. (2002, p. 36), que afirmam que "O terceiro planalto, ou Planalto de Guarapuava, encontra-se, do ponto de vista geológico, representado exclusivamente por derrames basálticos da Formação Serra Geral e por bancos arenosos do Grupo Bauru".

O solo característico do Terceiro Planalto, de acordo com Medri et al. (2002), originou-se de rochas eruptivas basálticas e, próximo à foz do rio Tibagi, é composto de latossolo roxo e terra roxa estruturada (latossolo e nitossolo). A classificação climática do Baixo Tibagi é o clima subtropical úmido (Cfa), com temperatura média de $21{ }^{\circ} \mathrm{C}$ e média pluviométrica de $1.600 \mathrm{~mm}$.

De acordo o Plano Diretor Municipal de Cornélio Procópio (2007, p. 24):

As regiões de maiores declividades localizam-se nas porções noroeste, incluindo a sub-bacia do ribeirão Tangará até o interflúvio entre as sub-bacias dos ribeirões Macuco e São Luís, nestes locais a declividade média é superior a 20\%. O extremo Sul, que compreende as sub-bacias dos ribeirões Braúna e Água do Pico Roxo, possui declividades medias acima de $15 \%$.

O trecho urbano do ribeirão Tangará (figura 2), objeto de estudo do diagnóstico ambiental, compreende parte do alto curso do ribeirão, que tem na região ao entorno o bairro Jardim Primavera, o Conjunto Habitacional José Benedito Catarino, o Conjunto Habitacional Professora Martha Dequech e o Jardim Novo Horizonte. Além disso, localiza-se na região da nascente a Integrada Cooperativa Agroindustrial.

Analisando a imagem do percurso urbano do ribeirão Tangará, é possível observar que a área está passando por transformações devido à instalação dos novos bairros, assim como a ocorrência de focos de queimadas. O percurso corresponde a aproximadamente $3 \mathrm{~km}$ do ribeirão.

Figura 2. Alto curso do ribeirão Tangará, localizado no município de Cornélio Procópio (PR).

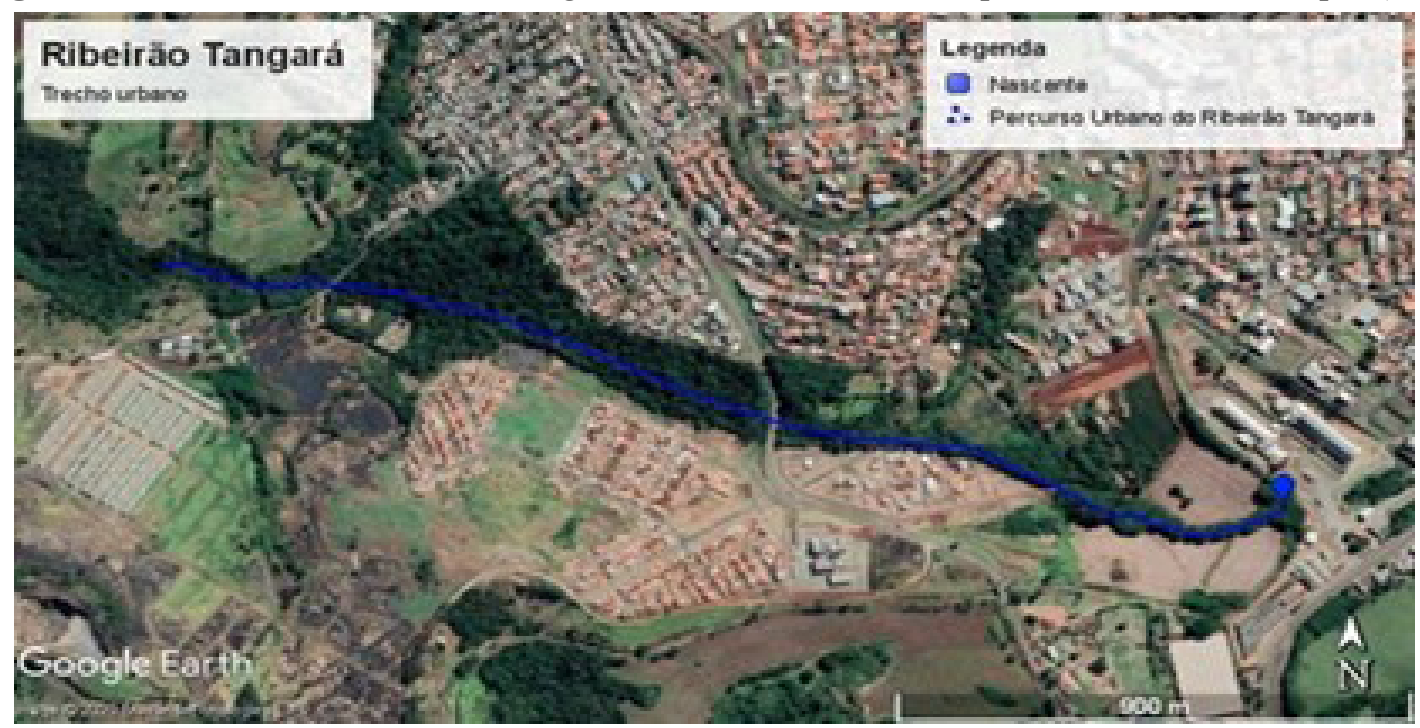

Fonte: Google Earth (2020). 


\section{Metodologia}

Metodologicamente, a pesquisa está orientada em duas frentes: a realização de um diagnóstico ambiental do trecho urbano do alto curso do ribeirão Tangará, onde se localiza a nascente do rio; e o emprego de ferramentas geotecnológicas para a elaboração de materiais voltados à Educação Ambiental. As etapas compreenderam:

1. Reconhecimento inicial da área de estudo: trabalho de campo realizado para reconhecimento do local, aferimento de localizações e averiguação das hipóteses levantadas;

2. Mapeamento do ribeirão Tangará: para o mapeamento foram utilizadas as ferramentas Google Earth e Google My Maps. Além disso, empregaram-se bases cartográficas de referência, como as cartas topográficas da região de estudo - Cornélio Procópio (SF.22-Z-G-I-2, MI-2759-2) e Uraí (SF.22Z-C-I-1, MI-2759-1);

3. Diagnóstico ambiental: realização das análises in situ. Buscou-se com o diagnóstico levantar as informações de cunho ambiental da área. Após isso, as informações foram sistematizadas e discutidas para obtenção dos resultados. O diagnóstico foi realizado por meio de visitas no local, com o auxílio do Google Earth para aferição das faixas de matas ciliares e para visualização holística da paisagem local. O diagnóstico ambiental e a sistematização dos dados orientaram-se pela proposta de Rodrigues et al. (2015), que estabeleceu seis critérios de análise. Os critérios utilizados pelo autor são de classificação qualitativa e quantitativa (valor, ordem, espaço, tempo, dinâmica e plástica), conforme o Quadro 1;

Quadro 1. Matriz para avaliação dos impactos ambientais.

\begin{tabular}{|c|c|c|c|}
\hline Aspectos & P. A & $\mathbf{P} / \mathbf{S}$ & Descrição dos parâmetros \\
\hline Valor/efeito & $\begin{array}{l}\text { Negativo } \\
\text { Positivo } \\
\text { Nulo }\end{array}$ & $\begin{array}{l}\mathrm{N} \\
\mathrm{P} \\
\mathrm{O}\end{array}$ & $\begin{array}{l}\text { Resulta na possibilidade de ocorrer um impacto de caráter significativo. } \\
\text { Resulta no benefício das atividades ou impactos da APP. } \\
\text { Resulta em um fator cujos efeitos inexistem. }\end{array}$ \\
\hline Ordem & $\begin{array}{l}\text { Direto } \\
\text { Indireto }\end{array}$ & $\begin{array}{l}\mathrm{D} \\
\mathrm{I}\end{array}$ & $\begin{array}{l}\text { Resulta de uma simples relação de causa e efeito. } \\
\text { Resulta de uma ação secundária ou quando é parte de uma cadeia de reações, } \\
\text { também denominada de impacto secundário. }\end{array}$ \\
\hline $\begin{array}{l}\text { Espaço/ } \\
\text { Escala }\end{array}$ & $\begin{array}{l}\text { Local } \\
\text { Regional } \\
\text { Estratégico }\end{array}$ & $\begin{array}{l}\text { Lo } \\
\text { Re } \\
\mathrm{E}\end{array}$ & $\begin{array}{l}\text { Quando afeta apenas a área/local do empreendimento. } \\
\text { Quando o efeito extrapola a área de implantação do empreendimento. } \\
\text { Quando o efeito assume reflexo estadual ou nacional. }\end{array}$ \\
\hline Dinâmica & $\begin{array}{l}\text { Temporário } \\
\text { Permanente } \\
\text { Cíclico }\end{array}$ & $\begin{array}{l}\mathrm{T} \\
\mathrm{Pe} \\
\mathrm{C}\end{array}$ & $\begin{array}{l}\text { Quando o efeito do impacto permanece por um determinado tempo, após o qual } \\
\text { desaparece. } \\
\text { Quando os efeitos não cessam de se manifestar num horizonte temporal conhecido. } \\
\text { Quando os efeitos se fazem sentir de forma cíclica ou periódica. }\end{array}$ \\
\hline Tempo & $\begin{array}{l}\text { Curto } \\
\text { Médio } \\
\text { Longo }\end{array}$ & $\begin{array}{l}\mathrm{C} \\
\mathrm{Me} \\
\mathrm{L}\end{array}$ & $\begin{array}{l}\text { A ação permanece num curto espaço de tempo. } \\
\text { A ação pode ser cessada após um tempo. } \\
\text { O impacto pode ser considerado irreversível. }\end{array}$ \\
\hline Plástica & $\begin{array}{l}\text { Reversível } \\
\text { Irreversível }\end{array}$ & $\begin{array}{l}\mathrm{R} \\
\mathrm{Ir}\end{array}$ & $\begin{array}{l}\text { O local pode voltar a ter a paisagem original. } \\
\text { Após a ação impactante, mesmo com medidas mitigadoras, o local não volta a ter a } \\
\text { paisagem original. }\end{array}$ \\
\hline Magnitude & $\begin{array}{l}\text { Pequena } \\
\text { Média } \\
\text { Grande }\end{array}$ & $\begin{array}{l}1-3 \\
4-6 \\
7-10\end{array}$ & $\begin{array}{l}\text { O meio permanece inalterado. } \\
\text { O meio apresenta uma leve alteração quanto à sua paisagem, porém de forma } \\
\text { inexpressiva. } \\
\text { A ação altera toda a paisagem. }\end{array}$ \\
\hline Frequência. & $\begin{array}{l}\text { Baixa } \\
\text { Média } \\
\text { Alta }\end{array}$ & $\begin{array}{l}1 \\
2 \\
3\end{array}$ & $\begin{array}{l}\text { Sem danos ou com danos mínimos ao meio ambiente. } \\
\text { O meio apresenta leve alteração quanto à sua paisagem, porém de forma } \\
\text { inexpressiva. } \\
\text { A ação altera toda a paisagem. }\end{array}$ \\
\hline Significância & $\begin{array}{l}\text { Não } \\
\text { significativa } \\
\text { Moderada } \\
\text { Significativa }\end{array}$ & $\begin{array}{l}1-3 \\
4-6 \\
7-9\end{array}$ & $\begin{array}{l}\text { O impacto provocado não altera a qualidade de vida do meio ou do homem. } \\
\text { A área lesionada pela ação, quando negativa, pode ser recuperada e, quando } \\
\text { positiva, apresenta uma melhoria razoável na qualidade de vida. } \\
\text { A ação impactante apresenta significativa evolução benéfica ao meio ambiente, } \\
\text { quando positiva, e perda na qualidade de vida, quando negativa. }\end{array}$ \\
\hline
\end{tabular}

Fonte: Rodrigues et al. (2015). 
4. Cartilha virtual: buscando uma alternativa para inserir o estudo no ensino, em temas correlatos à Educação Ambiental, foi elaborada uma cartilha virtual do ribeirão Tangará no formato de site. Criada a partir do Google Sites, teve por finalidade difundir conhecimento e informações a respeito de Educação Ambiental e do ribeirão Tangará.

\section{Resultados}

Através do diagnóstico, foi possível constatar que o trecho urbano sofre atualmente com descarte inadequado de resíduos sólidos (figuras 3 e 4) e a mata ciliar está comprometida pela ação humana, visto que em alguns locais foi suprimida.

\section{Figura 3 - Resíduos sólidos descartados inadequadamente em área de mata ciliar do ribeirão Tangará.}

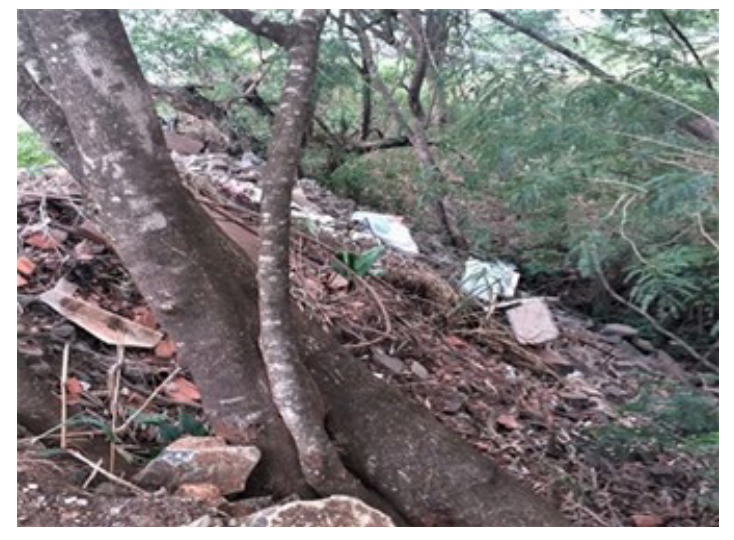

Figura 4 - Resíduos sólidos descartados inadequadamente no leito do ribeirão Tangará.

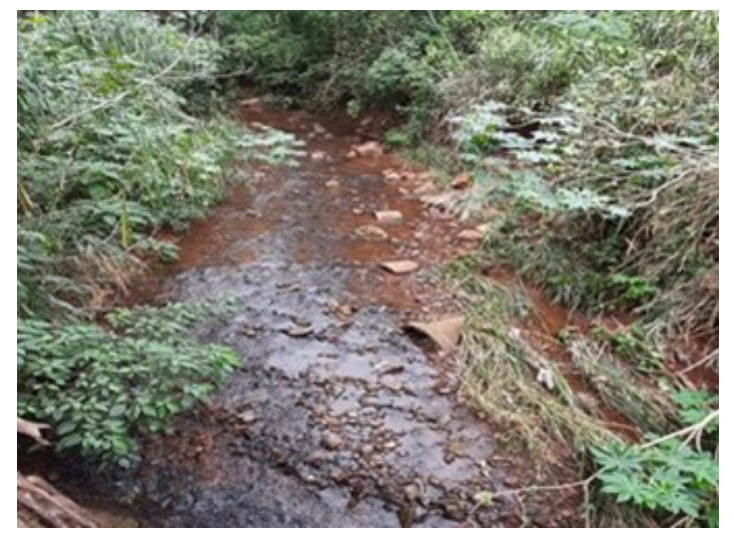

A falta e modificação da mata ciliar podem causar efeitos negativos para o meio. Por este motivo, a Lei $n^{\circ} 12.651 / 2012$ estabelece que cursos d'água menores que 10 metros de largura, como o trecho de estudo do ribeirão Tangará, perenes ou intermitentes, devem ter 30 metros de faixa de vegetação acompanhando as margens do canal hídrico.

Conforme Schäffer et al. (2011, p. 13), "as APPs, juntamente com as Reservas Legais (no caso dos imóveis rurais), com a sua cobertura vegetal protegida, exercem um efeito tampão, reduzindo a drenagem e carregamento de substâncias e elementos para os corpos d'água [...]". As florestas ripárias oferecem sombreamento a água do rio, favorecendo para controle de sua temperatura, assim como contribuem para a qualidade do habitat,

[...] funcionam como fonte de fornecimento adequado de nutrientes para as populações de organismos aquáticos e silvestres e agem como filtros de sedimentos, material orgânico, fertilizantes, pesticidas e outros poluentes que podem afetar de forma adversa os corpos de água e as águas subterrâneas. Cada uma destas funções exercida pelas florestas ripárias está associada a uma zona da floresta e às características próprias da floresta [...]. (SCHÄFFER et al., 2011, p. 13)

A partir do Google Earth, foi realizada a medição da mata ciliar ao redor da nascente, em uma circunferência, e a medida encontrada foi de aproximadamente 31 metros de raio. Considerando a Lei n ${ }^{\circ} 12.651 / 2012$, a qual estabelece um raio mínimo de 50 metros ao redor de nascente e olhos d'água, a nascente do ribeirão Tangará não está dentro dos critérios. No entanto, há de se levar em conta que a mata ciliar ao redor da nascente não segue um padrão circular e, considerando a mata exterior ao raio medido, conforme figura 5, em linha reta, a nascente possui cerca de 27 metros de mata ciliar.

Figura 5 - Nascente do ribeirão Tangará.

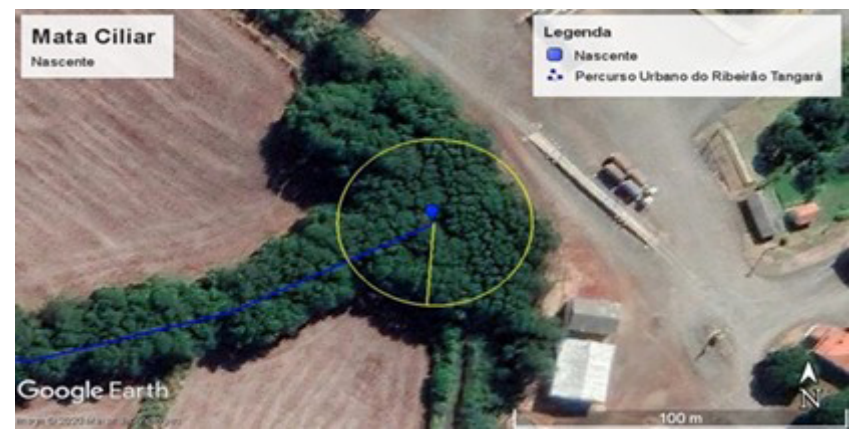

Fonte: Google Earth (2020).

Da nascente até aproximadamente 276 metros à jusante do ribeirão, a vegetação varia de 11 a 20 metros, menos da metade do que a lei estabelece (figura 6). 
A margem esquerda do ribeirão apresenta estado mais crítico, pois em alguns pontos a vegetação não chega a 12 metros de extensão da faixa de mata ciliar. O local onde se encontra a Estação de Tratamento de Esgoto (ETE), também na margem esquerda do ribeirão, foi construída respeitado o limite da mata ciliar de 30 metros. Nos demais trechos da margem esquerda do trecho de estudo do ribeirão Tangará, que compreende aproximadamente 3 metros, a mata ciliar está de acordo com o estabelecido pela lei. A margem direita do ribeirão possui a mata ciliar de acordo com as APP e, em alguns pontos medidos, ela ultrapassa os 30 metros exigidos pela lei.

Figura 6 - Área de mata ciliar do trecho urbano do ribeirão Tangará.

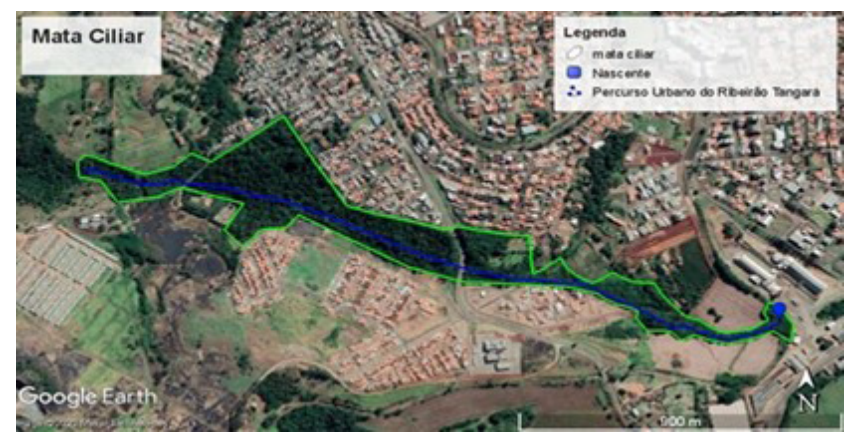

Fonte: Google Earth (2020).

Como se nota na figura 6 , também é possível constatar uma ocupação por atividade agrícola próximo à nascente. Essas atividades podem resultar em efeitos negativos ao ribeirão, segundo Sarcinelli et al. (2008, p. 74):

A invasão das áreas de preservação da vegetação ripária por sistemas agrícolas é uma das principais causas da perda dos serviços ambientais prestados por este ecossistema. A proximidade extrema das áreas de cultivo junto aos corpos d'água potencializa os efeitos negativos da erosão sobre a hidrologia do córrego, ao mesmo tempo em que reduz sua capacidade de vazão, a qualidade e a quantidade de água disponível para consumo.

De acordo com Schäffer et al. (2011), as APP possuem algumas funções ambientais. Uma delas é preservar a paisagem, pois, quando em áreas urbanas, deixam o ambiente prazeroso à população, garantindo cidades mais sustentáveis; outra função extremamente importante das APP é conservar a estabilidade geológica. Segundo o autor, áreas de declive superior a $45 \%$, se desmatadas ou degradadas, podem contribuir para a intensificação de processos erosivos, deslizamentos de solos e rochas, causando impactos negativos ao local.

[...] uma vez desmatadas, degradadas e/ou indevidamente ocupadas, perdem a proteção conferida pela vegetação ciliar, ficando sujeitas aos efeitos de desbarrancamentos e deslizamentos de solo ou rochas e o consequente carreamento de sedimentos para o leito dos rios, promovendo seu assoreamento. Com isso os rios tornam-se mais rasos, e nas situações de precipitações mais volumosas, não conseguem conter o volume adicional de água, potencializando cheias e enchentes. (SCHÄFFER et al., 2011, p. 15)

No trecho de estudo foi encontrado um poste de eletricidade caído na mata ciliar do ribeirão (figura 7). Provavelmente ele caiu em virtude da proximidade com o ribeirão e/ou em um período de cheia, o que também é frequente, visto que a ponte que liga o Conjunto Habitacional José Benedito Catarino ao centro da cidade já sofreu com os impactos da cheia do ribeirão e teve que ser restaurada (PREFEITURA..., 2018).

Figura 7 - Poste de eletricidade tombado em área de mata ciliar do ribeirão Tangará.

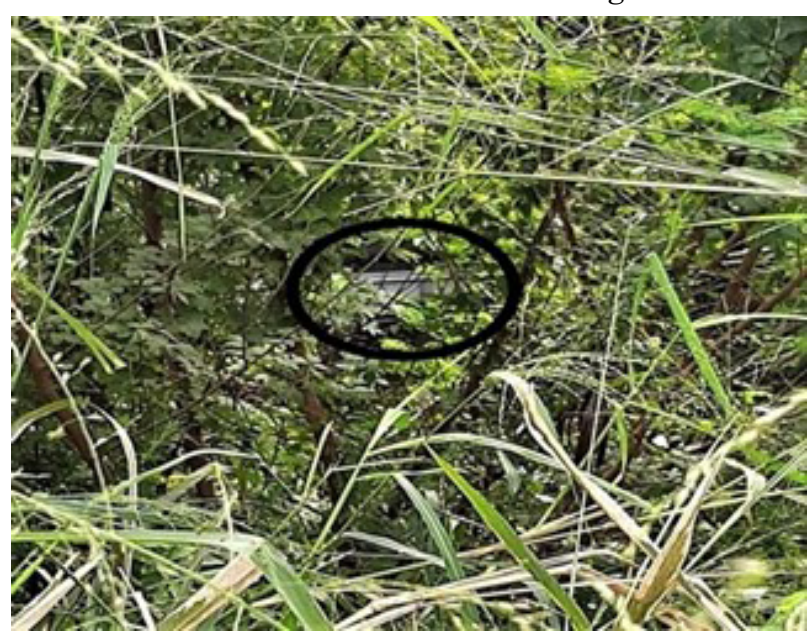

Uma possível explicação para esse caso é justamente a proximidade com que o poste foi instalado e o desrespeito ao curso natural do rio, como é apontado por Guerra et al. (2008):

A cobertura florestal natural das encostas, dos topos de morros, das margens de rios e córregos existe para proteger o solo da erosão provocada por chuvas, permite a alimentação dos lençóis d'água e a manutenção de nascentes e rios, e evita que a água da chuva provoque inundações rápidas (enxurradas). 
As APP têm grande importância para a biodiversidade, protegendo a fauna e a flora. Segundo Sá, Verani e Fragoso (2003), "[...] nos pequenos riachos das cabeceiras, folhas mortas e galhos são as fontes primárias de carbono orgânico para as cadeias alimentares aquáticas, chegando a representar até $70 \%$ do fluxo de energia anual desses ecossistemas". De acordo com Schäffer et al. (2011), as APP formam "corredores ecológicos", sendo "[...] porções de ecossistemas naturais ou seminaturais, ligando áreas remanescentes de vegetação nativa entre si ou com unidades de conservação [...]". Ou seja, nessas áreas acontecem fluxos gênicos (troca de genes) e movimentos da biota, que proporcionam dispersão de espécies e reconstrução de áreas degradadas. Quando esses movimentos não acontecem, espécies ficam isoladas, diminuindo sua variedade genética e tornando-as menos adaptáveis às mudanças no ambiente. As APP têm papel importante na preservação do solo, uma vez que áreas onde a mata está preservada "[...] servem como filtro, evitando que impurezas cheguem aos corpos d'água e, ao mesmo tempo, protegem as margens contra a erosão, evitando o assoreamento dos rios e o agravamento das enchentes".

A ocorrência de chuvas torrenciais e a consequente elevação do nível de água dos riachos e rios é natural, sempre existiu e sempre existirá. Ou seja, onde houve enchente uma vez, mais cedo ou mais tarde, haverá novamente. Para prevenir as enchentes e evitar os prejuízos, a ação mais efetiva é não ocupar as áreas de risco, que via de regra são Apps, ou se a área alagável estiver ocupada, o melhor "remédio" é desocupá-la o mais rápido possível. (CAMPANILI; SCHAFFER, 2010, p. 8)

Portanto, as APP exercem importante função das margens de rios, encostas etc. Dessa forma, elas devem ser preservadas e respeitadas, a fim proteger os recursos naturais e a população. A partir do diagnóstico, foi possível avaliar os impactos ambientais encontrados no local, assim como estabelecer algumas medidas mitigadoras, conforme o quadro 2:

Quadro 2 - Avaliação dos impactos ambientais.

\begin{tabular}{|c|c|c|c|c|c|c|c|c|c|c|}
\hline Impactos & $\frac{0}{\frac{0}{\sigma}}$ & 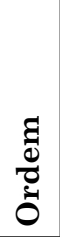 & 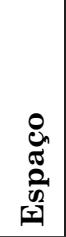 & 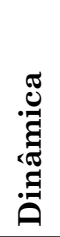 & 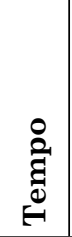 & 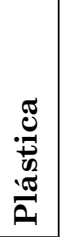 & 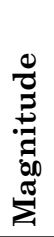 & 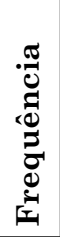 & 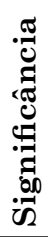 & Medidas mitigadoras \\
\hline $\begin{array}{l}\text { Descarte inadequado } \\
\text { de resíduos sólidos }\end{array}$ & $\mathrm{N}$ & $\mathrm{D}$ & Lo & $\mathrm{C}$ & $\mathrm{Me}$ & $\mathrm{R}$ & 5 & 2 & 5 & $\begin{array}{l}\text { Ações educativas voltadas aos moradores a respeito dos } \\
\text { impactos que os resíduos descartados inadequadamente } \\
\text { no local podem ocasionar. Instalações de pontos de } \\
\text { coleta de resíduos. }\end{array}$ \\
\hline $\begin{array}{l}\text { Modificação/retirada } \\
\text { da mata ciliar }\end{array}$ & $\mathrm{N}$ & $\mathrm{D}$ & Lo & $\mathrm{Pe}$ & $\mathrm{Me}$ & $\mathrm{R}$ & 5 & 2 & 5 & $\begin{array}{l}\text { Evitar novas alterações na mata ciliar e promover o } \\
\text { reflorestamento das áreas degradadas. }\end{array}$ \\
\hline
\end{tabular}

Legenda: N: negativo; D: direto, Lo: local; C: cíclico; Me: médio; R: reversível; Pe: permanente. Fonte: Adaptado de Rodrigues et al. (2015).

\section{Conclusões}

Constatou-se que o principal impacto ambiental no ribeirão Tangará é o descarte inadequado de resíduos sólidos, o qual, por sua vez, pode causar enchentes, poluição da água e poluição visual. Outro fator que contribui para a poluição do local são os novos bairros que estão sendo construídos ao redor da área de estudo. A mata ciliar do ribeirão deve ser respeitada para evitar novos danos ao meio e, possivelmente, novas enchentes. Dessa forma, políticas de preservação da área deveriam ser adotadas, a fim de minimizar os danos causados ao local.

A partir dos dados sistematizados, a cartilha virtual (figura 8) foi criada em formato de site, para divulgar informações sobre o ribeirão Tangará1. O objetivo do site é ser utilizado em sala de aula por professores da rede de ensino de Cornélio Procópio e região, assim como pela população em geral.

A pesquisa ainda abre margens para que novos estudos sobre o ribeirão Tangará sejam realizados, principalmente nas demais áreas da extensão do seu curso, como a região do baixo curso fluvial, que engloba a foz do ribeirão.

1 Disponível no endereço eletrônico https://sites.google. com/view/ribeiraotangara. 
Figura 8 - Cartilha virtual educativa em formato de website.

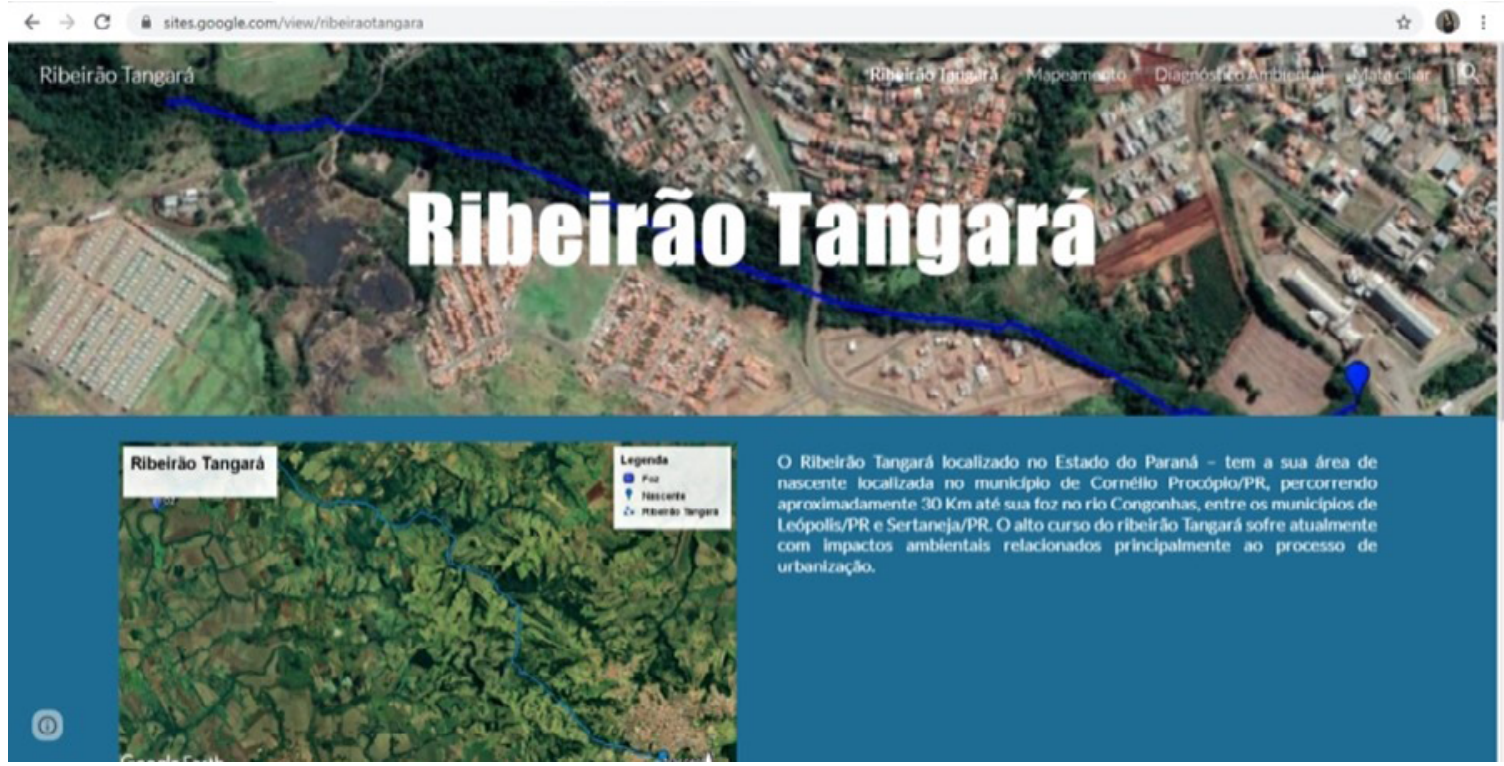

Fonte: Google Sites (2020).

\section{REFERÊNCIAS}

ABNT. ABNT NBR ISO 14001: sistemas da gestão ambiental: requisitos com orientação para uso. Rio de Janeiro: ABNT, 2015. Disponível em: https://www.ipen. br/biblioteca/slr/cel/N3127.pdf. Acesso em: 12 abr. 2020.

BRASIL. Lei n ${ }^{\circ} 12.651$, de 25 de maio de 2012. Dispõe sobre a proteção da vegetação nativa; altera as Leis n. ${ }^{\circ}$ s 6.938, de 31 de agosto de 1981, 9.393, de 19 de dezembro de 1996, e 11.428, de 22 de dezembro de 2006; revoga as Leis n. ${ }^{\circ} \mathrm{s} 4.771$, de 15 de setembro de 1965, e 7.754, de 14 de abril de 1989, e a Medida Provisória no 2.166-67, de 24 de agosto de 2001; e dá outras providencias. Diário Oficial da União, Brasília, DF, 28 maio 2012. Disponível em: https://bit.ly/3d1GNKJ. Acesso em: 23 abr. 2020.

BRASIL. Lei n ${ }^{\circ} 6.938$, de 31 de agosto de 1981. Dispõe sobre a Política Nacional do Meio Ambiente, seus fins e mecanismos de formulação e aplicação, e dá outras providências. Diário Oficial da União, Brasília, DF, 2 set. 1981. Disponível em: https://bit.ly/3xKmoS6. Acesso em: 2 maio 2020.

BRASIL. Lei n ${ }^{\circ}$ 9.795, de 27 de abril de 1999. Dispõe sobre a educação ambiental, institui a Política Nacional de Educação Ambiental e dá outras providências. Diário Oficial da União, Brasília, DF, 28 abr. 1999. Disponível em: https://bit.ly/35Id9pJ. Acesso em: 2 maio 2020.
BRASIL. Ministério da Educação. Secretaria de Educação Fundamental. Parâmetros curriculares nacionais: meio ambiente: saúde. 3. ed. Brasília, DF: Ministério da Educação, 2001.

BRASIL. Secretaria de Educação Fundamental. Parâmetros curriculares nacionais: meio ambiente e saúde. Brasília, DF: Ministério da Educação, 1997.

CAMPANILI, M.; SCHAFFER, W. (org.). Mata atlântica: patrimônio nacional dos brasileiros. Brasília, DF: Ministério do Meio Ambiente, 2010.

CAMPIANI, M. G. Os temas transversais na educação. São Paulo: Códex, 2001.

CORNÉLIO PROCÓPIO. Plano diretor municipal. Cornélio Procópio: [s. n.], 2007. Disponível em: https://bit.ly/3wQHyOx. Acesso em: 10 jul. 2020.

PREFEITURA de Cornélio Procópio conclui obras de recuperação da ponte sobre o Ribeirão Tangará. Cornélio Notícias, Cornélio Procópio, 11 maio 2018. Disponível em: https://bit.ly/3yxjocw. Acesso em: 10 jul. 2020.

FERNANDES, M. M. F. et al. Diagnóstico ambiental da faixa ciliar e qualidade de água de duas microbacias utilizadas para abastecimento humano. Irriga, Botucatu, v. 20, 
n. 1, p. 128-138, 2015. DOI: http://dx.doi.org/10.15809/ irriga.2015v20n1p128.

FERREIRA, G. et al. Análise socioambiental em propriedades rurais com nascentes em processo de recuperação no município de Lauro Muller (SC). Revista Giência \& Cidadania, Orleans, v. 2, n. 1, p. 92-102, 2016. Disponível em: https://bit.ly/3xGIXXV. Acesso em: 14 abr. de 2020.

GASS, S. L. B. et al. Áreas de Preservação Permanente (APPs) no Brasil e na França: um comparativo. Confins, Aubervilliers, n. 27, 2016. DOI: https://doi.org/10.4000/ confins. 10829 .

GUERRA, A. F. S. et al. Criação do código ambiental catarinense: uma reflexão sobre as enchentes e deslizamentos. FloripAmanhã, Florianópolis, 2 dez. 2008. Disponível em: https://bit.ly/3gNRUcq. Acesso em: 25 ago. 2020.

\section{GUIMARÃES, M. A dimensão ambiental na ed-} ucação. Campinas: Papirus, 1995.

MEDRI, M. E. et al. (ed.). A bacia do rio Tibagi. Londrina: [s.n.], 2002.

MENDONÇA, F. Geografia e meio ambiente. São Paulo: Contexto, 1993.

MENDONÇA, F. Geografia socioambiental. Terra livre, São Paulo, n. 16, p. 113-132, 2001.

MENDONÇA, H. Na tragédia de Minas, o descaso da administração encontra os efeitos da mudança climática. El País, Madri, 29 jan. 2020. Disponível em: https:// bit.ly/3gOE1uo. Acesso em: 23 abr. 2020.

\section{MOREIRA, I. V. D. Vocabulário Básico do meio ambiente. Rio de Janeiro: Feema, 1992.}

MOTA, S. Urbanização e meio ambiente. 3. ed. Rio de Janeiro: Abes, 2003.

PEREIRA, M. G. B.; SCROCGARO, J. L. (org.). Bacias hidrográficas do Paraná: série histórica. Curitiba: Secretaria do Estado do Meio Ambiente e Recursos Hídricos, 2010.
RODRIGUES, A. J. et al. Diagnóstico ambiental de um trecho da área de preservação permanente (APP), margens do córrego pouso do meio, em Gurupi-TO. Enciclopédia Biosfera, Goiânia, v. 11, n. 21, p. 31033113, 2015.

SÁ, M. F. P.; VERANI, N. F.; FRAGOSO, E. N. Peixes do cerrado em perigo. Giência Hoje, Rio de Janeiro, v. 34, n. 200, p. 68-71, 2003.

SANTANA, M. N. R. Identificação dos impactos ambientais da ocupação irregular na área de preservação permanente (APP) do Córrego Tamanduá em Aparecida de Goiânia. In: CONGRESSO BRASILEIRO DE GESTÃO AMBIENTAL, 2., 2011, Londrina. Anais [...]. Bauru: Ibeas, 2011. p. 1-5. Disponível em: https:// bit.ly/3gXufFe. Acesso em: 2 maio 2020.

SANTOS, E. M. D.; FARIA, L. C. M. D. O educador e o olhar antropológico. Fórum Grítico da Educação, Rio de Janeiro, v. 3, n. 1, p. 9-20, 2004.

SARGINELLI, O.; MARQUES, J. F.; ROMEIRO A. R. Custo de adequação ambiental das áreas de vegetação ripária: estudo de caso na microbacia do Córrego Oriçanguinha, SP. Revista Informações Econômicas, São Paulo, v. 38, n. 10, p. 70-79, 2008.

SCHÄFFER, W. B. et al. Áreas de preservação permanente e unidades de conservação $x$ áreas de risco: o que uma coisa tem a ver com a outra? Brasília, DF: Ministério do Meio Ambiente, 2011. Relatório de Inspeção.

SILVA, T. G. N. et al. Diagnóstico ambiental de uma área de proteção permanente (APP), Formoso do Araguaia - TO.

Revista da Universidade Vale do Rio Verde, Três Corações, v. 16, n. 2, p. 1-10, 2018. DOI: http://dx.doi.org/ 10.5892/ruvrd.v16i2.4619.

VEYRET, Y. Géo-environnement. Paris: Sedes, 1999.

VIANNA, A. M. Poluição ambiental, um problema de urbanização e crescimento desordenado das cidades. Sustinere, Rio de Janeiro, v. 3, n. 1, p. 22-42, jul. 2015. DOI: https://doi.org/10.12957/sustinere.2015.17325. 